\title{
Lessons learned from MPI and physiologic testing in randomized trials of stable ischemic heart disease: COURAGE, BARI 2D, FAME, and ISCHEMIA
}

\section{Citation}

Phillips, Lawrence M., Rory Hachamovitch, Daniel S. Berman, Ami E. Iskandrian, James K. Min, Michael H. Picard, Raymond Y. Kwong, et al. 2013. Lessons Learned from MPI and Physiologic Testing in Randomized Trials of Stable Ischemic Heart Disease: COURAGE, BARI 2D, FAME, and ISCHEMIA. J. Nucl. Cardiol. 20, no. 6: 969-975. doi:10.1007/s12350-013-9773-4.

\section{Published Version}

doi:10.1007/s12350-013-9773-4

\section{Permanent link}

http://nrs.harvard.edu/urn-3:HUL.InstRepos:29048902

\section{Terms of Use}

This article was downloaded from Harvard University's DASH repository, and is made available under the terms and conditions applicable to Other Posted Material, as set forth at http:// nrs.harvard.edu/urn-3:HUL.InstRepos:dash.current.terms-of-use\#LAA

\section{Share Your Story}

The Harvard community has made this article openly available.

Please share how this access benefits you. Submit a story.

Accessibility 


\title{
Lessons learned from MPI and physiologic testing in randomized trials of stable ischemic heart disease: COURAGE, BARI 2D, FAME, and ISCHEMIA
}

\author{
Lawrence M. Phillips, MD ${ }^{a}$, Rory Hachamovitch, MD, MSc ${ }^{b}$, Daniel S. Berman, MD $^{c}$, Ami E. $^{2}$ \\ Iskandrian, MD $^{d}$, James K. Min, MD ${ }^{e}$, Michael H. Picard, MD ${ }^{f}$, Raymond Y. Kwong, MD ${ }^{g}$, \\ Matthias G. Friedrich, MD ${ }^{h}$, Marielle Scherrer-Crosbie, MD, PhD $^{f}$, Sean W. Hayes, MD $^{c}$, Tali \\ Sharir, MDi, Gilbert Gosselin, MD ${ }^{\mathrm{h}}$, Marco Mazzanti, MDj, Roxy Senior, MD ${ }^{\mathrm{k}}$, Rob \\ Beanlands, MD', Paola Smanio, MD ${ }^{m}$, Abhi Goyal, MD, MHS ${ }^{n}$, Mouaz Al-Mallah, MD ${ }^{\circ}$, \\ Harmony Reynolds, MDa, Gregg W. Stone, MDp${ }^{\mathrm{p}}$, David J. Maron, MDq, and Leslee J. Shaw, \\ PhD $^{n}$ \\ aNew York University School of Medicine, New York, NY \\ ${ }^{b}$ Cleveland Clinic Foundation, Cleveland, $\mathrm{OH}$ \\ ${ }^{\circ}$ Cedars-Sinai Medical Center, Los Angeles, CA \\ dUniversity of Alabama - Birmingham, Birmingham, AL \\ eWeill Cornell Medical College, New York, NY \\ 'Massachusetts General Hospital, Boston, MA \\ gBrigham and WomenGúøs Hospital, Boston, MA \\ hMontreal Heart Institute, Montreal, QC, Canada \\ 'Assuta Medical Center, Tel Aviv, Israel \\ JUniversity Hospital of Ancona, Ancona, Italy \\ kNorthwick Park Hospital, London, United Kingdom \\ 'Ottawa Heart Institute, Ottawa, ON, Canada \\ mInstituto Dante Pazzanese de Cardiologia, São Paulo, Brazil \\ nEmory University School of Medicine, Atlanta, GA \\ oKing Abdulaziz Cardiac Center, Riyadh, Saudi Arabia \\ pNew York Presbyterian Hospital/Columbia University Medical Center, New York, NY \\ qVanderbilt University, Nashville, TN
}

\section{Abstract}

There is a preponderance of evidence that, in the setting of an acute coronary syndrome, an invasive approach using coronary revascularization has a morbidity and mortality benefit. However, recent stable ischemic heart disease (SIHD) randomized clinical trials testing whether the addition of coronary revascularization to guideline-directed medical therapy (GDMT) reduces 
death or major cardiovascular events have been negative. Based on the evidence from these trials, the primary role of GDMT as a front line medical management approach has been clearly defined in the recent SIHD clinical practice guideline; the role of prompt revascularization is less precisely defined. Based on data from observational studies, it has been hypothesized that there is a level of ischemia above which a revascularization strategy might result in benefit regarding cardiovascular events. However, eligibility for recent negative trials in SIHD has mandated at most minimal standards for ischemia. An ongoing randomized trial evaluating the effectiveness of randomization of patients to coronary angiography and revascularization as compared to no coronary angiography and GDMT in patients with moderate-severe ischemia will formally test this hypothesis. The current review will highlight the available evidence including a review of the published and ongoing SIHD trials.

\section{Keywords}

Myocardial perfusion imaging; ischemia; coronary artery disease; clinical trials

\section{INTRODUCTION}

There is a preponderance of evidence that, in the setting of an acute coronary syndrome, an invasive approach using coronary revascularization has a well-established morbidity and mortality benefit. ${ }^{1-3}$ However, the results from recent stable ischemic heart disease (SIHD) randomized clinical trials are inconclusive as to whether the addition of coronary revascularization to guideline-directed medical therapy (GDMT) reduces death or major cardiovascular events. Based on data from observational studies, it has been hypothesized that there is a level of ischemia above which a revascularization strategy might result in benefit regarding cardiovascular events. However, eligibility for recent negative trials in SIHD mandated only minimal standards for ischemia. ${ }^{4,5}$ The current review will highlight the available evidence regarding the potential role of ischemia in guiding decisions for revascularization in SIHD.

\section{CONCEPTS OF RISK-BASED DECISION MAKING}

A prominent reason for referral to stress imaging [myocardial perfusion single photon emission computed tomography (SPECT) or positron emission tomography (PET), stress echocardiography, or stress cardiac magnetic resonance imaging (CMR)] is to assess prognosis through the provocation of ischemia and correlates with presenting chest pain or other symptom equivalents. The extent and severity of myocardial ischemia are wellestablished prognosticators, with recent SIHD guidelines supporting Class I indications for its use in SIHD patients. ${ }^{6,7}$ Thus, once myocardial ischemia has been identified, the second step is to delineate its extent and severity. There is a well-defined relationship between the extent and severity of myocardial ischemia and the rate of occurrence of major coronary artery disease (CAD) events. ${ }^{8}$ In a classic publication by Hachamovitch et al, ${ }^{9}$ the extent and severity of myocardial ischemia directly correlated with incidence of cardiac death and MI (Figure 1). In this observational series, increases in the summed stress score, a measure of the combined extent and severity of stress perfusion abnormality, predicted higher rates of MI and death; a summed stress score of $>13$ was associated with an annual MI risk of $4.2 \%$. In epidemiologic terms, this is defined as a proportional or graded relationship whereby patients with moderate-severe ischemia have the highest CAD event rates. The risk associated with more severe ischemia appears to be multiplicative above that of patients with low risk stress imaging findings. ${ }^{10}$ Clinically, using risk-based decision making, patients are categorized from low to high risk subsets in order to identify those requiring more intensive preventive efforts and anti-ischemic therapy, matching intensity of treatment 
to CAD event risk. ${ }^{10}$ For this highest risk group with moderate-severe ischemia, the intensity of management is also graded to include index GDMT with safe deferral of coronary revascularization as based on recent SIHD trials. ${ }^{11}$

Despite this theorem which generally applies to high risk ischemia patients, the optimized treatment strategy of GDMT with or without revascularization is ill-defined. Based on current randomized trial evidence, the role of intensive GDMT as a front line medical management approach has been clearly defined and has been detailed in the recent SIHD clinical practice guidelines, while the role of prompt revascularization is imprecisely defined and will be discussed herein. ${ }^{11}$

\section{EXPLORATORY ANALYSIS ON THERAPEUTIC RISK REDUCTION FOR PATIENTS WITH SIHD}

Observational studies in SIHD patients indicate that revascularization in the setting of moderate to severe myocardial ischemia is associated with a survival benefit over medical therapy alone; although the quality and intensity of medical therapy was not documented. ${ }^{12,13}$ This can be in the form of direct treatment with pharmacologic therapy or lifestyle modification. ${ }^{14}$

There are additional observational series in patients with left ventricular systolic dysfunction in which the aim is to identify hibernating and ischemic myocardium. ${ }^{15,16}$ In these reports, a threshold of ischemia associated with an improved survival following prompt revascularization was not reported. Moreover, in a recent secondary analysis from NIHNHLBI-sponsored Surgical Treatment for IsChemic Heart Failure (STICH) trial, survival was similar for patients with and without ischemia and there was no interaction between ischemia and treatment for any of the trial endpoints. ${ }^{17}$ These cohorts with left ventricular dysfunction support that current data fail to support a threshold of ischemia whereby early revascularization is associated with improved cardiac outcomes.

\section{ISCHEMIA-GUIDED MEDICAL AND SURGICAL MANAGEMENT Clinical Outcomes Using Revascularization and Aggressive Drug Evaluation (COURAGE) Trial}

The Department of Veterans' Affairs-sponsored COURAGE trial randomized a total of 2,287 SIHD patients with significant CAD and site-defined evidence of myocardial ischemia to a strategy of GDMT or GDMT plus revascularization with percutaneous intervention (PCI). A proximal epicardial stenosis of at least $70 \%$ had to be accompanied by ST segment depression or $\mathrm{T}$ wave inversions on the resting electrocardiogram or inducible ischemia on EKG or perfusion during stress testing. If at least $80 \%$ proximal epicardial stenosis was present in patients with classic angina symptoms, stress testing was not required. In terms of the severity of ischemia, minimal criteria were applied for trial eligibility including the presence of a stress-induced defect in one or more myocardial segments. In a recent subset analysis of patients undergoing pre-treatment stress MPI, $\sim 60 \%$ had no to mild ischemia at the time of randomization. ${ }^{18}$ The main trial results revealed that the primary endpoint of allcause death or MI was reached in $19.0 \%$ of the GDMT plus PCI group and $18.5 \%$ of the GDMT arm $(P=.62) .{ }^{4}$ Although the main trial results were negative, interesting findings were reported on differences in symptoms based on randomization. The Seattle Angina Questionnaire scores within subscales of angina frequency and stability improved in both the GDMT alone and the GDMT plus PCI arms. ${ }^{19}$ An incremental, statistically significant, improvement was initially seen in the GDMT plus PCI arm as compared to the GDMT alone arm through 36 months of follow-up. However, by 5 years of follow-up, nearly three-fourths of patients enrolled in the COURAGE trial were angina-free. ${ }^{4,19}$ 
These results revealed interesting differences in provocative symptoms and were further evaluated within a nuclear substudy that enrolled a total of 314 patients. ${ }^{20}$ In this substudy, patients underwent serial MPI where differences in quantification were compared from prerandomization and again at $\sim 1$ year of follow-up ${ }^{20,21}$ (Figure 2). Specifics of the protocol have been provided in detail. ${ }^{21}$ In brief, the baseline MPI was performed prior to initiation of randomized treatment, following discontinuation of anti-ischemic therapy for 24-48 hours. For this substudy, the primary endpoint was a post-treatment reduction of $25 \%$ ischemic myocardium using quantitatively evaluated total perfusion defects including both defect extent and severity. ${ }^{22}$ While significant reduction in ischemic myocardium was observed in both treatment groups, a greater reduction was seen in the trial patients randomized to PCI with GDMT as compared to GDMT alone (33\% vs $19 \%, P=.0004){ }^{20}$ Concomitant reductions in angina were also reported with these noted reductions in ischemia. One of the most striking findings from this substudy was the significant change reported for patients with moderate-severe myocardial ischemia at the time of randomization. In patients with moderate-severe ischemia, the majority of patients in the PCI arm had a significant reduction in percent ischemic myocardium (78\%) as compared to those randomized to GDMT alone $(52 \%, P=.007)$. Even with pre-treatment testing being performed while holding anti-ischemic and anti-cholesterol lowering medications, these reductions are striking. These results were hypothesis generating but suggest that there may be a differential benefit of ischemia reduction for patients with moderate as compared to mild ischemia.

Earlier analyses explored the role of pre-treatment ischemia as exerting an influential effect on randomized treatment. ${ }^{12}$ In a small subset analysis of patients with site-defined three ischemic segments (out of a total of 6 segments visually assessed), there was no difference in clinical outcomes for patients that were randomized to PCI plus GDMT as compared to GDMT alone $(P=.44)$. This secondary analysis was underpowered but calls for additional research that may aid in the targeted development of SIHD strategies aimed at this higher risk cohort of patients with moderate-severe ischemia.

\section{Bypass Angioplasty Revascularization Investigation 2 Diabetes (BARI 2D) Trial}

Following the COURAGE trial, the results from the National institutes of Health-National Heart, Lung, and Blood Institute (NIH-NHLBI)-sponsored BARI 2D trial were reported. ${ }^{5} \mathrm{~A}$ total of 2,368 SIHD patients with CAD and type 2 diabetes were randomized to medical therapy (MED) or MED plus revascularization with a second randomization based on insulin-sensitization vs insulin-provision therapy. Patients were required to have at least one epicardial coronary artery stenosis $>50 \%$ on coronary angiography with a positive stress test or $>70 \%$ with classic angina. Patients with significant left main stenosis or unstable clinical status were excluded. There was no reduction in the primary endpoint of death from any cause $(11.7 \%$ vs $12.2 \%, P=.97)$ or the principal secondary outcome of major cardiovascular events (composite of death, myocardial infarction, or stroke) $(77.2 \%$ vs $75.9 \%, P=.70$ ) with revascularization over GDMT alone. $42.1 \%$ of patients who were initially assigned to GDMT alone crossed over to revascularization within the 5-year followup period. This reinforces the fact that both BARI 2D and COURAGE compared initial management strategies, but many patients assigned to medical therapy alone eventually underwent revascularization during the follow-up period. ${ }^{4,5}$

As part of BARI 2D, a total of 1,505 patients underwent adenosine stress MPI at $~ 1$ year post-randomization using quantitative core lab interpretation ${ }^{23,24}$ (Figure 3). Prerandomization MPI results were not available. Similar to the results of the COURAGE nuclear substudy, at 1 year of follow-up, less myocardial ischemia was observed in the revascularized arm compared to the MED group. Quantitative perfusion evaluations showed 
median $\%$ ischemic myocardium of $2 \%$ (interquartile range: $2 \%-10 \%$ ) for the MED group vs $0 \%$ (interquartile range: $0 \%-7 \%)$ for the revascularized patients $(P<.0001)$. There was no difference by randomized treatment in the \% fixed myocardium $(P=.85)$, supporting earlier trial results of a reduced ischemic burden following targeted anti-ischemic therapeutic management. ${ }^{25}$

Additional analyses on the 1-year adenosine SPECT scan revealed that a decreased poststress left ventricular ejection fraction and moderately to severely abnormal MPI scans were associated with increased rate of CAD death or MI. ${ }^{18}$ At 1-year, the 5-year rates of cardiac death or MI were $11.3 \%, 8.1 \%$, and $6.8 \%$, respectively, for $\pm 10 \%, 5 \%-9.9 \%$, and $1 \%-4.9 \%$ abnormal myocardium at stress $(P<.0001)$. In risk-adjusted models, the relative hazard for CAD death or MI was 1.11 for every $5 \%$ increase in \% abnormal myocardium at stress $(P$ $=.004)$.

A final analysis compared the \% ischemic or abnormal myocardium as an interaction with randomized treatment and, similar to the COURAGE trial findings, these results were not statistically significant. These results should also be viewed as exploratory analyses, given the small sample size and the fact that this analysis was not an a priori defined subset analyses.

\section{FRACTIONAL FLOW RESERVE VS ANGIOGRAPHY FOR MULTIVESSEL EVALUATION (FAME) TRIALS}

In the Fractional Flow Reserve vs Angiography for Multivessel Evaluation (FAME) trial, a total of 1,005 patients with known multivessel CAD were randomized to routine PCI vs FFR-guided PCI for patients with ischemia, defined as an FFR measurement of 0.80 or less. ${ }^{26}$ In the FAME trial, patients were followed for only 1 year with the primary endpoint of death, MI, or repeat revascularization. The main trial findings revealed a primary endpoint of $18.3 \%$ in the routine PCI arm as compared to $13.2 \%$ in the FFR-guided PCI arm $(P=.02)$. Similar findings were reported after 2 years of follow-up. ${ }^{27}$

As a follow-up to this initial trial, the FAME-2 trial randomized a total of 888 patients with CAD and FFR $<0.8$ to medical therapy vs FFR-guided PCI plus medical therapy. ${ }^{28}$ Prior to completion of the designated follow-up evaluation, the trial's data safety monitoring board recommended enrollment be stopped after an interim analysis revealed a highly statistically significant decrease in unplanned hospitalization leading to urgent revascularization in the PCI arm. This drove a significant reduction in the primary endpoint (death, MI, or hospitalization for urgent revascularization) for FFR-guided PCI plus medical therapy as compared to medical therapy alone [hazard ratio (HR) $0.32,95 \%$ confidence interval (CI) $0.19-0.53, P<.0001$ ], as there was no significant difference in mortality (HR 0.33, CI 0.03$3.17, P=.31$ ) or MI (HR 1.05, CI 0.51-2.19, $P=.89$ ). Had COURAGE and BARI 2D included urgent revascularization as a component of their primary endpoints, they might also have found a significant difference between treatment groups. In FAME 2, there was an $83 \%$ risk reduction with urgent revascularization in the PCI plus GDMT arm as compared to GDMT alone.

In a meta-analysis by Christou et al, ${ }^{29}$ the concordance of FFR $<0.75$ against abnormal nuclear stress testing had a sensitivity of $75 \%$ (95\% CI 66\%-82\%) and specificity $77 \%$ (95\% CI 70\%-83\%). However, prospective analysis of patients with multivessel CAD on angiography, showed only a $42 \%$ concordance in specific ischemic territories between MPI and FFR. ${ }^{30}$ Accordingly, one might envision clinically evident discordance between FFR and stress test evidence of ischemia. 


\section{EVIDENCE SYNTHESIS IN THE SIHD GUIDELINE}

In the 2012 ACCF/AHA/ACP/AATS/PCNA/SCAI/ STS Guideline for the Diagnosis and Management of Patients with SIHD, revascularization is recommended for survival benefit in patients with three-vessel CAD (>70\% stenosis) or two-vessel disease including the proximal LAD (Class I indication) independent of myocardial ischemia evaluation. For patients with two-vessel disease, extensive myocardial ischemia as derived from stress testing, FFR, or viability testing should be the basis for defining a clinical benefit with revascularization. Yet, thresholds for moderate-severe ischemia are not clearly defined and the negative evidence with the COURAGE and BARI 2D trials does not support a survival benefit with revascularization.

A potential explanation for failure of revascularization to reduce the incidence of death or MI in prior SIHD strategy trials is that lower risk patients were permitted into these trials, diluting the power to show a benefit from revascularization. Restricting the study population to only higher risk SIHD patients with more severe and extensive ischemia may be required to demonstrate a reduction in death or MI from revascularization. However, this is purely speculative and requires putting forth a testable hypothesis comparing revascularization as compared to medical therapy approaches in SIHD patients with moderate-severe ischemia.

\section{ONGOING INTERNATIONAL STUDY OF COMPARATIVE HEALTH EFFECTIVENESS WITH MEDICAL AND INVASIVE APPROACHES(ISCHEMIA) TRIAL}

In July 2012, enrollment began for the NIH-NHLBI sponsored ISCHEMIA trial. Over 8,000 SIHD patients worldwide will be randomized to an initial invasive strategy of cardiac catheterization, revascularization, and GDMT as compared to an initial conservative strategy of GDMT alone with cardiac catheterization reserved for those who fail medical therapy. In the ISCHEMIA trial, enrolled patients will have core laboratory determined ischemia on stress MPI (PET or SPECT), echocardiography, or CMR (wall motion or perfusion) with the goal of moderate-severe ischemia. ${ }^{31}$ This is in contrast to COURAGE and BARI 2D where enrollment was not predicated on core laboratory confirmation of any significant degree of ischemia. ${ }^{4,5}$ The rationale for including multiple imaging modalities is to enhance the generalizability of findings to the diverse modalities that are available to practicing clinicians caring for SIHD patients around the globe.

There was considerable discussion on defining comparable definitions of moderate-severe ischemia for MPI, echocardiography, and CMR. Although the trial investigators examined numerous approaches, it was agreed upon that MPI ischemia that achieved an annual CAD death or MI rate of 5\% would be the threshold for the other modalities. For MPI, this is defined as $\geq 10 \%$ ischemic myocardium. This measurement can be made by a combination of a quantitative evaluation of $\geq 10 \%$ ischemic myocardium or semi-quantitative assessment of a summed difference score of $>6$, using a 17 segment model and a maximum score of 4 per segment. For stress echocardiography evaluation, moderate ischemia is defined as $\geq 3$ segments with stress-induced severe hypokinesis or akinesis. For CMR, moderate ischemia was defined as $\geq 12 \%$ stress perfusion defect without late gadolinium enhancement, or $\geq 3$ segments with stress-induced severe hypokinesis or akinesia. Since patients will not undergo cardiac catheterization prior to randomization, a blinded CCTA is performed to exclude patients with significant left main stenosis or no obstructive CAD. The primary endpoint will be a composite of cardiovascular death or MI with secondary endpoints including angina-related quality of life and cost. This trial will be completed in $\sim 2019$. 
The ISCHEMIA trial hypotheses attempt to demonstrate the extent to which an angiographic-driven strategy for higher risk SIHD patients with moderate-severe ischemia will or will not improve clinical outcomes. The clinical community has struggled with the application of SIHD strategies based on the negative COURAGE and BARI 2D trials. Thus, support of this important trial should be encouraged within the nuclear and all of the imaging community due to ISCHEMIA being the first trial mandating a threshold extent and severity of ischemia as fundamental to SIHD management. The potential implications for either GDMT or angiographically driven care for the MPI community are immense and could provide the solid evidence base to identify optimal candidates for intensive antiischemic management.

\section{CONCLUSIONS}

An emphasis on individualized, patient-centered imaging requires identification of patients who benefit from revascularization in addition to GDMT for reduction in angina as well as improvements in reducing incident death or MI. Advanced cardiovascular imaging successfully risk stratifies patients in many situations. Although follow-up in both COURAGE and BARI 2D showed greater reduction in MPI ischemia for revascularization, a morbidity and mortality benefit was not observed in either trial. Whether stress imaging guided decisions on the use of angiography or GDMT result in improved clinical outcomes remains an unproven hypothesis but is currently being evaluated within the ongoing ISCHEMIA trial. We have come a long way in our knowledge but continue to have many questions to answer in the question of ischemia-guided management.

\section{References}

1. Mehta SR, Cannon CP, Fox KA, Wallentin L, Boden WE, Spacek R, et al. Routine vs selective invasive strategies in patients with acute coronary syndromes: A collaborative meta-analysis of randomized trials. J Am Med Assoc. 2005; 293:2908-17.

2. Lagerqvist B, Husted S, Kontny F, Stahle E, Swahn E, Wallentin L. 5-Year outcomes in the FRISCII randomized trial of an invasive versus a non-invasive strategy in non-ST-elevation acute coronary syndrome: A follow-up study. Lancet. 2006; 368:998-1004. [PubMed: 16980115]

3. Lakkis N, Tsyboulev V, Gibson CM, Murphy SA, Weintraub WS, DiBattiste PM, et al. Outcome of patients with acute coronary syndrome admitted to hospitals with or without onsite cardiac catheterization laboratory: A TACTICS-TIMI 18 substudy. Crit Pathw Cardiol. 2002; 1:232-7. [PubMed: 18340309]

4. Boden WE, O'Rourke RA, Teo KK, Hartigan PM, Maron DJ, Kostuk WJ, et al. Optimal medical therapy with or without PCI for stable coronary disease. N Engl J Med. 2007; 356:1503-16. [PubMed: 17387127]

5. Frye RL, August P, Brooks MM, Hardison RM, Kelsey SF, Mac-Gregor JM, et al. A randomized trial of therapies for type 2 diabetes and coronary artery disease. N Engl J Med. 2009; 360:2503-15. [PubMed: 19502645]

6. Beller GA, Zaret BL. Contributions of nuclear cardiology to diagnosis and prognosis of patients with coronary artery disease. Circulation. 2000; 101:1465-78. [PubMed: 10736294]

7. Shaw LJ, Iskandrian AE. Prognostic value of gated myocardial perfusion SPECT. J Nucl Cardiol. 2004; 11:171-85. [PubMed: 15052249]

8. Shaw L, Achenbach S, Narula J. Anatomy trumps all! JACC Cardiovasc Imaging. 2013; 6:745-6. doi:10.1016/j.jcmg.2013.05.001. [PubMed: 23764103]

9. Hachamovitch R, Berman DS, Shaw LJ, Kiat H, Cohen I, Cabico JA, et al. Incremental prognostic value of myocardial perfusion single photon emission computed tomography for the prediction of cardiac death: Differential stratification for risk of cardiac death and myocardial infarction.

Circulation. 1998; 97:535-43. [PubMed: 9494023]

10. Califf RM, Armstrong PW, Carver JR, D'Agostino RB, Strauss WE. 27th Bethesda conference: Matching the intensity of risk factor management with the hazard for coronary disease events. 
Task Force 5. Stratification of patients into high, medium and low risk subgroups for purposes of risk factor management. J Am Coll Cardiol. 1996; 27:1007-19. [PubMed: 8609316]

11. Fihn SD, Gardin JM, Abrams J, Berra K, Blankenship JC, Dallas AP, et al. 2012 ACCF/AHA/ ACP/AATS/PCNA/SCAI/STS guideline for the diagnosis and management of patients with stable ischemic heart disease: A report of the American College of Cardiology Foundation/American Heart Association Task Force on Practice Guidelines, and the American College of Physicians, American Association for Thoracic Surgery, Preventive Cardiovascular Nurses Association, Society for Cardiovascular Angiography and Interventions, and Society of Thoracic Surgeons. J Am Coll Cardiol. 2012; 60:e44-164. doi:10.1016/j.jacc.2012.07.013. [PubMed: 23182125]

12. Hachamovitch R, Hayes SW, Friedman JD, Cohen I, Berman DS. Comparison of the short-term survival benefit associated with revascularization compared with medical therapy in patients with no prior coronary artery disease undergoing stress myocardial perfusion single photon emission computed tomography. Circulation. 2003; 107:2900-7. [PubMed: 12771008]

13. Moroi M, Yamashina A, Tsukamoto K, Nishimura T. J-ACCESS Investigators. Coronary revascularization does not decrease cardiac events in patients with stable ischemic heart disease but might do in those who showed moderate to severe ischemia. Int J Cardiol. 2012; 158:246-52. [PubMed: 21342709]

14. Califf RM, Armstrong PW, Carver JR, D'Agostino RB, Strauss WE. 27th Bethesda conference: Matching the intensity of risk factor management with the hazard for coronary disease events. Task Force 5. Stratification of patients into high, medium and low risk subgroups for purposes of risk factor management. J Am Coll Cardiol. 1995; 27:1007-19. [PubMed: 8609316]

15. Kwon DH, Hachamovitch R, Popovic ZB, Starling RC, Desai MY, Flamm SD, et al. Survival in patients with severe ischemic cardiomyopathy undergoing revascularization versus medical therapy: Association with end-systolic volume and viability. Circulation. 2012; 126:S3-8. [PubMed: 22965991]

16. Ling LF, Marwick TH, Flores DR, Jaber WA, Brunken RC, Cerqueira MD, et al. Identification of therapeutic benefit from revascularization in patients with left ventricular systolic dysfunction: Inducible ischemia versus hibernating myocardium. Circ Cardiovasc Imaging. 2013; 6:363-72. [PubMed: 23595888]

17. Panza JA, Holly TA, Asch FM, She L, Pellikka PA, Velazquez EJ, et al. Inducible myocardial ischemia and outcomes in patients with coronary artery disease and left ventricular dysfunction. $\mathrm{J}$ Am Coll Cardiol. 2013; 61:1860-70. [PubMed: 23500234]

18. Shaw LJ, Weintraub WS, Maron DJ, Hartigan PM, Hachamovitch R, Min JK, et al. Baseline stress myocardial perfusion imaging results and outcomes in patients with stable ischemic heart disease randomized to optimal medical therapy with or without percutaneous coronary intervention. Am Heart J. 2012; 164:243-50. [PubMed: 22877811]

19. Weintraub WS, Spertus JA, Kolm P, Maron DJ, Zhang Z, Jurkovitz C, et al. Effect of PCI on quality of life in patients with stable coronary disease. N Engl J Med. 2008; 359:677-87. [PubMed: 18703470]

20. Shaw LJ, Berman DS, Maron DJ, Mancini GB, Hayes SW, Hartigan PM, et al. Optimal medical therapy with or without percutaneous coronary intervention to reduce ischemic burden: Results from the Clinical Outcomes Utilizing Revascularization and Aggressive Drug Evaluation (COURAGE) trial nuclear substudy. Circulation. 2008; 117:1283-91. [PubMed: 18268144]

21. Shaw LJ, Heller GV, Casperson P, Miranda-Peats R, Friedman J, Hayes SW, et al. Gated myocardial perfusion single photon emission computed tomography imaging in the Clinical Outcomes Utilizing Revascularization and Aggressive Drug Evaluation trial. J Nucl Cardiol. 2006; 13:685-98. [PubMed: 16945749]

22. Slomka PJ, Nishina H, Berman DS, Akincioglu C, Abidov A, Friedman JD, et al. Automated quantification of myocardial perfusion SPECT using simplified normal limits. J Nucl Cardiol. 2005; 12:66-77. [PubMed: 15682367]

23. Iskandrian AE, Heo J, Mehta D, Tauxe EL, Yester M, Hall MB, et al. Gated SPECT perfusion imaging for the simultaneous assessment of myocardial perfusion and ventricular function in the BARI 2D trial: An initial report from the nuclear core laboratory. J Nucl Cardiol. 2006; 13:83-90. [PubMed: 16464721] 
24. Shaw LJ, Cerqueira MD, Brooks MM, Althose AD, Sansing VV, Beller GA, et al. Impact of left ventricular function and the extent of ischemia and scar by stress myocardial perfusion imaging on prognosis and therapeutic risk reduction in diabetic patients with coronary artery disease: Results from the bypass angioplasty revascularization investigation 2 diabetes (BARI 2D) trial. J Nucl Cardiol. 2012; 19:658-69. [PubMed: 22527794]

25. Mahmarian JJ, Shaw LJ, Olszewski GH, Pounds BK, Frias ME, Pratt CM, et al. Adenosine sestamibi SPECT post-infarction evaluation (INSPIRE) trial: A randomized, prospective multicenter trial evaluating the role of adenosine Tc-99m sestamibi SPECT for assessing risk and therapeutic outcomes in survivors of acute myocardial infarction. J Nucl Cardiol. 2004; 11:45869. [PubMed: 15295415]

26. Tonino PA, De Bruyne B, Pijls NH, Siebert U, Ikeno F, van't Veer M, et al. Fractional flow reserve versus angiography for guiding percutaneous coronary intervention. N Engl J Med. 2009; 360:213-24. [PubMed: 19144937]

27. Pijls NH, Fearon WF, Tonino PA, Siebert U, Ikeno F, Bornschein B, et al. Fractional flow reserve versus angiography for guiding percutaneous coronary intervention in patients with multivessel coronary artery disease: 2-year follow-up of the FAME (Fractional Flow Reserve Versus Angiography for Multivessel Evaluation) study. J Am Coll Cardiol. 2010; 56:177-84. [PubMed: 20537493]

28. De Bruyne B, Pijls NH, Kalesan B, Barbato E, Tonino PA, Piroth Z, et al. Fractional flow reserveguided PCI versus medical therapy in stable coronary disease. N Engl J Med. 2012; 367:9911001. [PubMed: 22924638]

29. Christou MA, Siontis GC, Katritsis DG, Ioannidis JP. Meta-analysis of fractional flow reserve versus quantitative coronary angiography and noninvasive imaging for evaluation of myocardial ischemia. Am J Cardiol. 2007; 99:450-6. [PubMed: 17293182]

30. Melikian N, De Bondt P, Tonino P, De Winter O, Wyffels E, Bartunek J, et al. Fractional flow reserve and myocardial perfusion imaging in patients with angiographic multivessel coronary artery disease. JACC Cardiovasc Interv. 2010; 3:307-14. [PubMed: 20298990]

31. [Accessed 31 July 2013] www.ischemiatrial.org. 


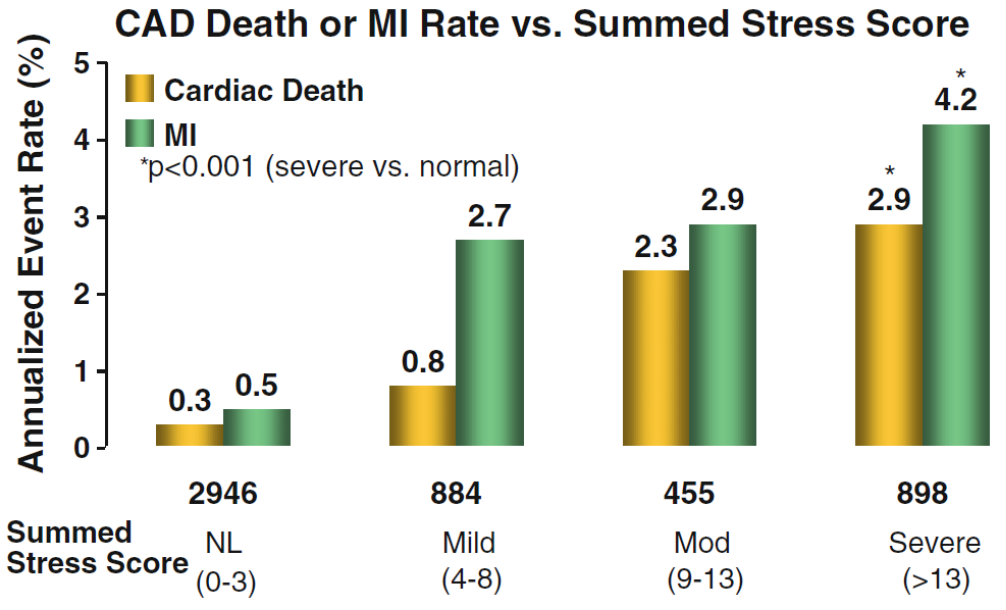

Figure 1.

Risk stratification with stress myocardial perfusion SPECT imaging. ${ }^{9}$ 

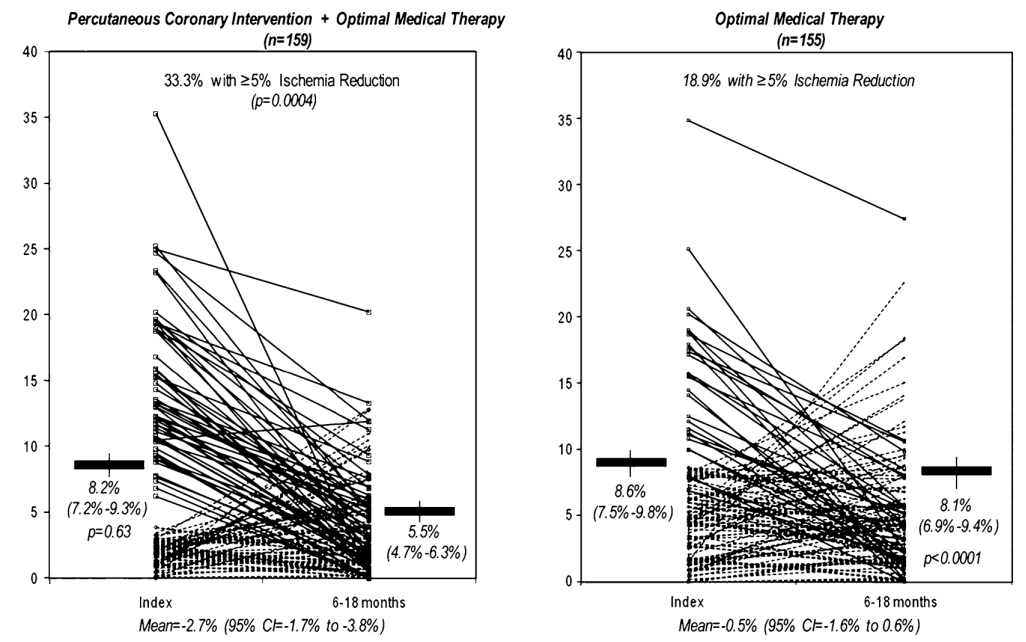

"Changes by treatment were adjusted by index ischeria. Dotted lines indicate no significantreduction in ischeria. Solid lines indicate $25 \%$

Figure 2.

COURAGE nuclear substudy comparison of inducible ischemia with MPS pre-treatment and after 6-18 months of OMT with or without PCI. ${ }^{20}$ 


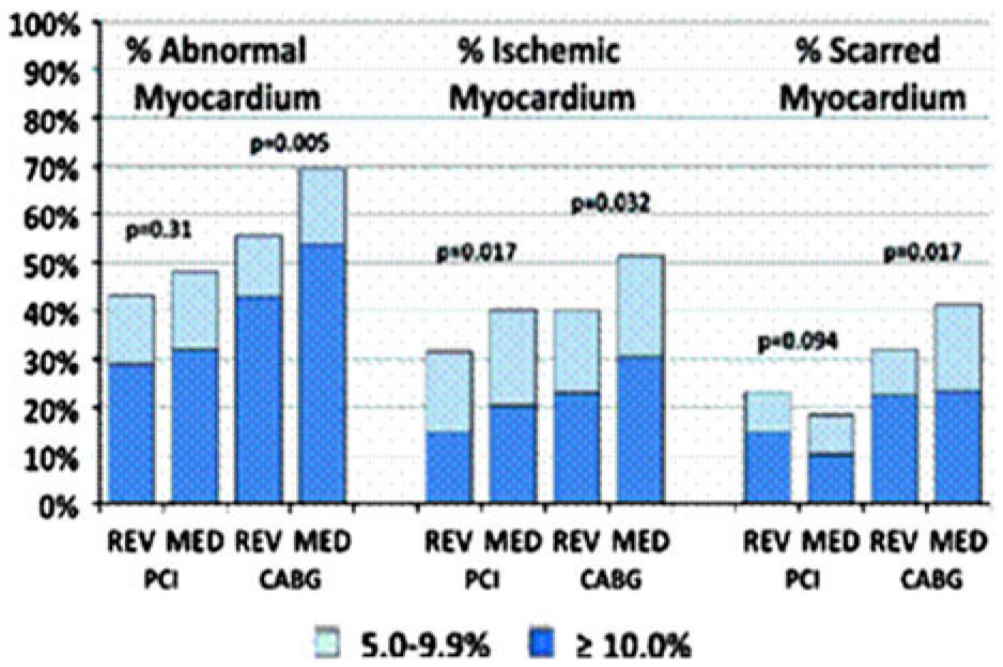

Figure 3.

BARI 2D extent and type of perfusion abnormality by stratum and assigned treatment. ${ }^{24}$ 